\title{
Internal branding: Exploring the employee's perspective
}

Received (in revised form): 12th November, 2007

\section{CERIDWYN KING}

is a lecturer at Griffith University, Gold Coast, Australia. She holds a Masters of Marketing Management with Honours and has had several years of strategic brand management experience in a range of industries. As an early career researcher, Ceridwyn has successfully published several papers in the area of internal brand management and continues to pursue this area of research in line with both academic and practitioner interest.

\section{DEBRA GRACE}

is a senior lecturer in marketing at Griffith University, Gold Coast,Australia. She holds a Bachelor of Business with Honours in Marketing and Management and a PhD in Marketing. Her research and teaching interests lie within the services marketing, branding and consumer behaviour areas. As such, she has a number of publications within journals that have their focus in these areas such as Journal of Service Research, Journal of Services Marketing, European Journal of Marketing and Journal of Retailing and Consumer Services.

\section{Keywords employees; brand commitment; internal branding}

Debra Grace

Department of Marketing, Griffith Business School, Griffith University, PMB 50,

Gold Coast Mail Centre 9726,

Queensland, Australia

Tel: 61755528027

Fax: 61755528085

E-mail: d.grace@griffith.edu.au

\section{Abstract}

The creation of a strong brand and the deliverance of perceived service quality are premised by employees' ability to deliver on customer expectations. No consideration has been given, however, to understanding the 'added value' encapsulated in an organisation's brand as a result of the operant resources (skills and knowledge) supplied by the organisation's human capital. This paper, therefore, explores the differential effect that internally oriented initiatives have on an organisation's human capital and its subsequent impact on the organisation's brand, from the employee's perspective. In-depth interviews were conducted with employees across a range of service industries and the results provide an insight into the creation of employee brand commitment. Furthermore, this exploratory study provides a solid platform for future research in this area.

Journal of Brand Management (2008) 15, 358-372. doi:10.1057/palgrave.bm.2550136; published online 7 December 2007

\section{INTRODUCTION}

Organisations, in today's competitive environment, continue in their struggle to carve out their competitive niche in the marketplace. In many cases, this struggle has manifested itself in the provision of exceptional service, regardless of whether the organisation's core product is a physical good or a service in its own right. ${ }^{1}$ Thus, we see a shift in thinking towards the new dominant logic for marketing, one in which the service (as manifested through operant resources), as opposed to the provision of physical goods (operand resources), is the basis for economic exchange. ${ }^{2}$ Consistent with the provision of exceptional service, investment in the organisation's brand is considered to be a strategic weapon in the quest for an edge over competitors. ${ }^{3}$ The creation of a strong brand and the deliverance of perceived service quality are premised by employees' ability to deliver on customer expectations. Thus, adoption of internal-oriented initiatives, ${ }^{4}$ directed at employees improving service quality and bringing the brand to life, is advocated. No consideration has been given, however, to understanding the 'added value' encapsulated in an organisation's brand as a result of the operant resources (skills and knowledge) supplied by the organisation's human 
capital. This paper, therefore, explores the differential effect that internally oriented initiatives have on an organisation's human capital and its subsequent impact on the organisation's brand. Moreover, this information is gleaned from the employees' perspective, rather than the commonly used perspectives of brand/marketing practitioners. ${ }^{5-7}$

\section{LITERATURE REVIEW}

The resource-based view of competitive advantage first appeared in the management literature over 20 years ago with a well-known article by Wernerfelt. ${ }^{8}$ Fundamentally, this view advocates that it is the superior resources and capabilities of an organisation that accommodate sustainability of competitive advantage. Resources are defined as 'elements, inputs or factors, from which the firm performs its activities' (Martin-de-Castro et al., ${ }^{9}$ p. 325). They are static by nature and, as such, they do not evolve but rather they wear out after continued use. ${ }^{10}$ Capabilities, on the other hand, arise from the combination and coordination of different resources ${ }^{11}$ and are embedded in organisational processes or routines. ${ }^{12}$ They emerge via a system of social interactions, which represent a continuous feedback between tacit and explicit knowledge. ${ }^{13}$ Unlike resources, they arise from conditions of uncertainty and complexity and, as a result of their dynamic nature, they can remain unchanged or improve through their use. ${ }^{14}$

The new service-centred dominant logic of marketing, promoted byVargo and Lusch, ${ }^{2}$ fundamentally, is based on a similar line of resource-based thought. Vargo and Lusch ${ }^{2}$ make a clear distinction between operand and operant resources. Operand resources are 'those resources on which an operation or act is performed to produce an effect' (Vargo and Lusch, ${ }^{2}$ p. 2). Operant resources, however, are resources that produce effects. ${ }^{15}$ They are intangible and often manifested as the firm's core competencies or processes. ${ }^{2}$ These inimitable resources, imbedded with an organisation's culture and capabilities, ${ }^{16}$ demand a strategic focus if competitive advantage is to be realised. As such, operant resources, as opposed to operand resources, are argued to be the primary unit of a marketing exchange and source of economic growth via the application and exchange of specialised knowledge and skills. ${ }^{2,17}$ This is supported by the management literature ${ }^{18,19}$ where it 'has been recognised for a long time that economic wealth comes from knowledge assets - intellectual capital—and its useful application'?

\section{Operant resources}

People possess skills, knowledge and experiences and, therefore, are of significant economic value to organisations. As these skills, knowledge and experiences enhance productivity, they represent capital that is too valuable to be lost. In fact, Ramlall ${ }^{20}$ stresses how important it is to recognise the commitment of individuals to the firm as well as providing an environment that is one in which individuals chose to stay. Thus, organisations must create an environment that supports its intellectual capital through the effective transmission of knowledge. Failure to do so may well result in the loss of valuable individual knowledge that has been developed through the length of the service. "This deep knowledge is what many believe will help to meet the needs and expectations of the customers and to create and sustain a competitive advantage within the global economy in which organisations are competing in today' (Ramlall, ${ }^{20}$ p. 53). One way to efficiently utilise knowledge in order to satisfy customer needs is through effective brand management. 


\section{Branding}

From an external market perspective, branding involves the creation of mental structures that help the target audience to organise their knowledge with respect to that particular product/organisation. In doing so, the target audience is able to clarify their decision making with respect to that product/organisation and, in turn, this process provides value to an organisation through improved customer buying habits. ${ }^{21}$ Branding, however, is not only an opportunity to shape customers' perceptions with respect to the organisation; it is also an opportunity to shape employee perceptions as well. ${ }^{22}$ In fact, according to Jacobs, ${ }^{23}$ a brand represents the relationship an organisation has with its employees just as much as it represents the relationship that it has with its customers.

In the context of pure services, it is the actual experience with the brand that dominates customer brand perceptions, of which employees play a major role. ${ }^{24}$ As such, regardless of how well the brand is presented, nothing will salvage a weak brand experience. ${ }^{22}$ Similarly, in relation to the marketing of physical goods, it is the employees who must understand what the brand means, and how it provides value to consumers, in order for its tangible and intangible components to be developed and delivered accordingly. It is for this primary reason that internal brand management is seen as a significant strategic organisational initiative. There is an inherent power in having an informed workforce that is both able and committed to delivering the brand promise. ${ }^{25}$ Without such brand knowledge, employees are unable to transform the brand vision into the brand reality. ${ }^{26}$

\section{Internal brand management}

At a basic level, Webster ${ }^{27}$ argues that 'human systems' or employees require 'glue' - a central theme upon which the employee can shape their behaviour so as to be consistent with consumer and organisational expectations. In the absence of such a bonding agent, employees may be directionless, struggling with knowing when, how and to whom to direct their energies. $^{27,28}$ In contrast, organisations that implement an employee-oriented service culture or 'internal service' are able to positively impact consumer confidence as a result of employees treating customers with greater respect. ${ }^{29}$ This is attributed to employees themselves feeling more respected and appreciated ${ }^{30}$ within their work environment.

Therefore, one can conclude that a central component to managing a customer's experience with a brand and their subsequent perceptions is to effectively manage employees' experiences within their own organisation. Through the internalisation of the brand, employees are better equipped to fulfil the explicit and implicit promises inherent in the brand ${ }^{22,26}$ and, therefore, expected by customers. This is because the desired brand values, practices and behaviours are clarified and defined, providing a clear direction for all organisational efforts. ${ }^{31}$ Without such internalisation, the ability for employees to deliver the appropriate customer experience is unlikely. In situations such as this, any external brand-building programme is likely to be unsuccessful. ${ }^{23}$ Without such brand knowledge, employees are unable to transform the brand vision into the brand reality. ${ }^{22,26}$

Realisation of human capital that is brand aware but, more importantly, able to deliver the brand promise demands the creation of a work environment that fosters encouragement as well as an appreciation and understanding of the organisation's employees. ${ }^{32}$ In fact, O'Reilly III and Pfeffer ${ }^{19}$ argue that effective strategy implementation not only requires the 
attraction and retention of great people but more importantly, the creation of a culture and a system that enables such employees to use their talents. Furthermore, such an environment facilitates organisational leverage of employee knowledge, wisdom and insight ${ }^{19}$ that is necessary for enhanced organisational decision making. Effective management, therefore, of employees, requires an internal market orientation (IMO), in the same way that managing the organisation-customer relationship requires an external market orientation. According to Lings $^{4}$ (p. 291), 'IMO involves the generation and dissemination of intelligence of information pertaining to the wants and needs of employees, and the design and implementation of appropriate responses to meet these wants and needs'. Such an internal approach to market orientation has emerged from the externally oriented market orientation literature (see, eg, Narver and Slater ${ }^{33}$ and Kohli and Jaworski ${ }^{34,35}$ ). Given the emphasis placed on the employee market in the realisation of organisational goals, expansion of the market orientation concept to incorporate internal, as well as external markets, is deemed to provide for a more holistic modern marketing model. ${ }^{4}$ As a result, realisation of an IMO results in the development of employee brand knowledge that enables the attraction and retention of, as well as motivation for, employees to deliver the brand promise.

According to Reichheld and Rogers ${ }^{36}$ (p. 20), 'getting the right people on board-and then all enthusiastically pulling in the right direction-has bedevilled organisations since the time of wooden ships, when the most popular form of motivation left lash marks'. Notwithstanding the cruelty of such a motivational technique, the essence of the act, that being to, figuratively speaking, 'kick someone in the pants (KITA)', as coined by Herzberg, is believed not to lead to motivation, but rather to movement. ${ }^{37}$ Such movement is not sustainable, nor does it lead to the much-coveted competitive advantage. In contrast, O'Reilly III and Pfeffer ${ }^{19}$ promote engaging employees in the business as an alternative to destroying their energy, knowledge and talent as a result of 'KITA'. Such an approach requires inspiring employees through setting clear goals ${ }^{36}$ that are well articulated, widely shared among the organisation and act as the foundation upon which the organisation's competitive advantage is built. ${ }^{19}$ Given that internal brand management is argued as being such a resource that engages and inspires employees to deliver the brand promise, and, therefore, deliver a competitive advantage, several research questions are posed to further understand how organisations engender an IMO. More importantly, though, such exploration will afford greater insight into the impact of these actions on the employee-brand relationship.

Therefore, the following research questions are posed.

RQ1: To what extent do employees understand what their organisation's brand represents?

RQ2: How do employees acquire organisational knowledge to help them carry out their roles and responsibilities in accordance with their organisation's brand promise?

RQ3: What factors are considered by employees to be necessary for them to successfully deliver their organisation's brand promise? 
RQ4: How does the organisation's internal market orientation impact employees' relationship with the brand?

The articulation of these research questions provides the necessary guidance to understand different organisational approaches to IMO and the subsequent results of such efforts. In doing so, further contribution to the existing body of knowledge with respect to internal brand management is realised.

\section{RESEARCH DESIGN}

The discovery-oriented nature of this research demanded a phenomenological approach to data gathering. The purpose of this study was to explore employees' perceptions of their organisation's brand and how that relates to their roles and responsibilities. Therefore, a qualitative approach was adopted due to it ability to obtain a first-hand description of a specified domain of experience. ${ }^{38,39}$ In this sense, understanding is derived from information gained directly from the employee, rather than from the direction of theories, laws and concepts. ${ }^{40}$

\section{Data collection}

The selection of in-depth interviews was deemed to be the most effective method of data collection to address the research questions due to the ability to obtain large amounts of data quickly, the ability to follow up and seek clarification and the need to rely only on a single primary method for gathering data. ${ }^{41}$ In addition, researchers in this area of study have extensively used in-depth interviews. ${ }^{7,42-44}$ As the objective of this study is to uncover and describe the participants' perspectives, use of in-depth interviews as the sole way of gathering data is deemed as an appropriate and sufficient methodology. ${ }^{41}$

So as to ensure this study answered the research questions, as well as to ensure consistency among the interviews, a measurement instrument, in the form of a semi-structured interview protocol, was developed. Based on the review of the literature, eight umbrella and 32 probing questions were developed to aid in the collection of data. The research questions along with the corresponding umbrella questions are shown in Table 1. Following a line of thought similar to that of Hastings and Perry, ${ }^{39}$ a convergent interviewing technique was used, whereby the interviews continued until there was zero sum gain from conducting anymore.

The interviews were audio taped and transcribed for ease of comprehensive and systematic analysis. This included a process of 'reduction' and 'interpretation'. ${ }^{41}$

\section{Participants}

Ten interviews were conducted with employees of organisations within the service industry. In particular, four interviews were conducted with employees who worked in the financial services industry. Of the four employees interviewed, three held middle-management positions and one was classified as holding an entry-level position. An additional two interviews were conducted with employees who worked in hospitality and both these employees were considered to be front-line or entrylevel employees. The remaining four interviews consisted of two from the banking industry and two from private education. With respect to both industries, a middle-level management employee as well as an entry-level employee was interviewed. 
Table I Research questions and corresponding interview questions (umbrella only)

\begin{abstract}
Research Question 1:To what extent do employees understand what their organisation's brand represents?

Research Question 2: How do employees acquire organisational knowledge to help them carry out their roles and responsibilities in accordance with their organisation's brand promise?
\end{abstract}

Research Question 3:What factors are considered by employees to be necessary for them to successfully deliver their organisation's brand promise?

Research Question 4: How does the organisation's internal market orientation impact employees' relationship with the brand?
Umbrella questions:

I. Can you explain to me in your own words what a brand is?

2. What does your organisation's brand stand for?

\section{Umbrella questions:}

I. Can you give me an overview as to the type of information your organisation gives to its employees? How do you receive this information (eg memos, email, newsletter, meeting and training)?

2. Can you give me an overview as to the type of information (feedback) that employees in your organisation give back to the organisation? How does this happen (eg informal, survey, meetings, etc)

Umbrella questions:

I. Can you explain to me how having knowledge about your customers' needs and expectations help you to know how to act in certain situations?

2. To what extent do you feel it is important for you as an employee to understand what has been promised/advertised in relation to the service you provide?

Umbrella questions:

I. To what extent do you feel it is important for you as an employee to understand what has been promised/advertised in relation to the service you provide?

2. We have talked about what the organisation advertises versus what is actually delivered-is there anything else that your organisation could implement that would ensure there was consistency between the advertised promise and the delivery?

\section{RESULTS AND DISCUSSION}

\section{RQ1: To what extent do employees understand what their organisation's brand represents?}

In general, the majority of participants were able to articulate (in varying degrees) what their organisation's brand represents. For example, six participants were able to adequately describe what their organisation's brand represented, and one of these participants was also able to elaborate on how their organisation differentiates itself from competitors. The remaining four participants, however, struggled to describe their organisation's brand or how they thought customers differentiated their organisation from competitors. In particular, one respondent felt that the brand was, in fact, the profession, believing there was limited difference in the various organisations operating within a profession. For example:

'Yeah-this industry I guess is a little bit different to some others in that it is a profession on it's own so you have few brands really-you have the major brand that most people work under-chartered accountants membership so that is really our primary brand from an employees perspective.... A lot of the firms' branding I suppose relies heavily on the chartered accountant's brand.'

Furthermore, with respect to the participants who could not succinctly articulate their brand, there appeared to be a theme that emerged from participants who worked in traditional, professional services such as education and accounting. As was evident in the above comment, the 
respondent's explanation of the brand was in fact the functional aspects of their profession, which was seen as quite separate from the actual organisation they worked for.

Collectively, though, the majority of the respondents were able to articulate certain aspects of their organisation that contribute to its overall brand image. The difference among the participants was in the detail provided. There was a clear distinction between the amount of content provided, with several participants launching into a lengthy explanation as opposed to others who provided a one-sentence response.

\section{RQ2: How do employees acquire organisational knowledge to help them carry out their roles and responsibilities in accordance with their organisation's brand promise?}

In relation to the way in which employees acquire organisational knowledge for the purpose of carrying out their roles and responsibilities, the results revealed three strong themes, that is, training, customer/ market information and work environment (co-workers).

\section{Training}

There was overwhelming consistency among participants that organisational training was not only provided but was also deemed important for the employees to be successful. For example, one participant commented

'They do a lot of training and spend time trying to get everyone to think the same way.'

When exploring the content provided in the formalised training sessions mentioned by the participants, it was obvious that 'technical direction' was the major focus. In other words, a very structured, systems and procedures-type approach to knowledge building was adopted, with the desired outcome being a satisfactory level of skill competency. For example, one respondent, who was employed in the gaming industry, when asked whether additional information (over and above skill training) was provided in their training sessions, commented:

'a little bit ......it's sort of just brushed over really, um they might spend 5 minutes on it when, you know, they give you that orientation book. They spend more time on how to sort coins. It's mostly technical ....they don't do anything else.'

As such, all participants saw the provision of training as something that their organisations did for the purpose of ensuring that employees have the necessary skills to satisfactorily perform their roles. This is not surprising, given that such training initiatives are seen as a means by which organisations can increase the consistency of the service provided, thereby increasing their control over the service encounter.

\section{Customer/market information}

Six of the participants reflected that, in addition to the training, their organisations give them the opportunity to be exposed to customer- and market-related information, whether that be in the form of customer feedback, customer initiatives employed by the organisation or competitors' activities. For example, one participant, when asked whether there was regular communication to employees about customers and general organisational information, commented:

'Every month-they share that information - the whole firm gets together and talks about new clients that have been approached, new clients that have come on board, new clients that have been targeted, clients that can't be targeted etc. They talk about many different things-it is all put out there.' 
At the other extreme, the rest of the participants commented that they were never exposed to additional information beyond the technical information. For example, one casino employee commented:

'I don't have a clue about what is going on in that casino, no idea.... They will have promotions and people will come to me and asked "where's the barrel to put this ticket in" and I will say "I dunno". I feel really, really rude doing that. I think we should be informed on different promotions and what is actually going on, more than what they do.'

Despite the literature suggesting that employees devoid of brand knowledge are unable to transform the brand vision into the brand reality, ${ }^{22,26}$ evidence presented here suggests that there is still an inconsistent practitioner approach to the provision of employee-relevant brand information. This is somewhat surprising, given that it is apparent from the comments provided by the participants who lacked customer or market information that employee satisfaction and their ability to successfully carry out their roles and responsibilities is adversely impacted. Despite the speed with which business decisions need to be made today in order to remain competitive, individuals within organisations are still not being given the support and skills they feel are necessary for them to respond effectively to the business challenges of today. ${ }^{45}$ The findings of this study suggest that 14 years on, such a reality is still prevalent in some organisations.

\section{Work environment-Co-workers}

Whether the organisation was perceived to be vigilant in the provision of information necessary for employee success, all participants (with the exception of one) reflected on the significance of their work environment in helping them to do their job. The role of co-workers in helping the organisational socialisation process was deemed to be significant. In particular, making the transition from a new employee to a productive employee was very much dependent on the employee's work environment. This is evidenced by the following comments:

'I guess when you leave one firm and go to another there are a lot of unknowns, a lot of uncertainties - you don't really know what to expect, you don't really know what it is going to be like .... that takes a while to learn. It is really just your experience and exposure to that and there is only so much you can read about and often things are written the way people want them to be and not necessarily the way they are - that can be a gap therebut you need to really need to get a feel for how the firm operates and I guess you have your antennas up when you first start and you really take in a lot of that information.'

'It's okay to have the culture wheel on the wall but they (employees) need to be exposed to how the current staff interact and go about their day.'

While the majority of the respondents indicated that their exposure to training and their work environment, in general, was productive in helping them to understand what they needed to do as an employee, there were differences in the extent to which they were exposed to customer or market information. Employees who did not receive this type of information indicated a desire to do so in order for them to do their job better. For example, a comment provided by one of the participants clearly reflects a personal level of dissatisfaction and frustration but also alludes to having an impact on organisational success and customer service levels.

'I wish I don't have to check with my supervisor because the customer will be 
like "oh you're a new staff member here" and I'm like "no I have been here for a year" but there a so much things going on here it is hard to keep track of.'

\section{RQ3: What factors are considered by employees to be necessary for them to successfully deliver their organisation's brand promise?}

The results of the interviews revealed a number of factors that were considered by respondents to be critical factors that needed to be present for them to be successful. Despite the differences in the knowledge that each respondent had with respect to their brand, there was a consistent theme flowing through all critical factors, that being the adoption of humanitarian approach to employees. In other words, respondents overwhelmingly noted that while the provision of information, whether that be in the form of training or customer/market communication, is important, what they perceive to be critical in order to be successful is the 'human factor'. For example, respondents identified that being acknowledged for your work was important for them to be successful, as is evident in the following comments:

'It (acknowledgement) is what makes you feel wanted and special I guess and also I guess from an employee's perspective from your management and the people you work for you want to know that there is a care factor there.'

'The people thing is necessary in order for me to do my job well.'

'What cements it for me is that I have the people there and that I can see a clear future and a future that I want to be part of.'

The attainment of favourable outcomes (eg employees able to deliver the brand promise) by the organisation is engendered through an exchange process between the employer and the employee. ${ }^{46}$ As such, it is only through the appropriate treatment of employees by the organisation that such outcomes are likely to be realised. Therefore, as the previous comments indicate, simply giving employees information is deemed to be insufficient to attract, retain and motivate employees to be brand champions. Rather, the development of long-term, mutually beneficial relationships between an employer and employee ${ }^{47,48}$ is advocated.

\section{RQ4: How does the organisation's internal market orientation impact employees' relationship with the brand?}

When exploring the impact that the various IMO initiatives had on the employees, all respondents used the essence of commitment to explain how their organisation's actions have impacted them. In recognition of the relational association between the employee and the organisation coveted by the respondents, as evidenced in the responses to research question three, it is not surprising that commitment is identified as a dominant impact. In fact, the importance placed on such a relationship from an employee's perspective is commensurate to the effort desired to maintain it. ${ }^{49}$ In other words, if the employee perceives the relationship with the organisation to be a positive one, worthy of maintaining, then the employee has a high level of commitment to the organisation.

Of the ten interviews conducted, there were two distinct levels of commitment, with only one participant indicating that they had no level of commitment whatsoever. With respect to the nine respondents who indicated that they were committed, six were strongly aligned to the organisation and its brand. Each of the 
respondents who indicated they were committed to the brand were very enthusiastic and seemed emotionally attached to their organisation's brand. Such overwhelming attachment is evidenced in the following comments:

'I love to be with this company-(why?) 'cause I love it here. It's hard to say because I have been very happy in all the branches I have ever worked in. I've never had any serious issues at all and if there ever has been any problems they have always been dealt with immediately there is always someone to go to ....X company do look after me.'

'X company spends a lot of time straight up talking about their philosophy and they tell you a lot of good stories about existing community banks that have donated so much to their local town it was quite powerful really to get you thinking "I wouldn't mind being a part of thatmaking a difference".

'If I stuff up or don't go the extra mile and make the customer happy-yeah I feel bad, definitely - that I am not doing my job properly that I have been paid for. I feel bad, personally, because you know this is the part of giving back to what I have been given.'

It was evident from the six interviewees who inadvertently 'swore a pledge of allegiance' to their brand that their organisation had been very successful in tapping into the motivational factors that Herzberg ${ }^{37}$ identified as needing to be intrinsic to the job, namely achievement, recognition for achievement, the work itself, responsibility and growth or advancement. In contrast, the remaining three interviews were void of such intrinsic qualities.

With respect to the remaining three interviewees who indicated that they were committed, the commitment was not so much for the brand but rather their profession. For example, the following comment was noted:

'I love my job....it is because I am passionate about the industry though not B Company'

Commitment is considered to be a key variable in determining organisational success, ${ }^{49}$ as employees' feeling of belonging influences their ability to go above and beyond the call of duty in order to achieve the organisation's goals. ${ }^{50}$ This is supported consistently within the findings of this research as is evidenced in the above comments. Failure to acknowledge the apparent linkage between the quality and quantity of IMO initiatives could result in a detrimental flow on effect beyond unsatisfied employees to dissatisfied, and ultimately defected, customers.

\section{Summary of results}

The results of this study provide a platform upon which practitioners can build their case for such an internal investment, by demonstrating the impact of IMO as manifested in employee commitment. With the premise of IMO being to align employee attitudes and behaviour for the ultimate benefit of the organisation, however, it is important to recognise that such a process is not without cynicism and resistance or the exhibition of negative attitudes from the target market (ie employees). In acknowledging the need to accept that such attitudes exist, Thomson ${ }^{51}$ argues that it is a requirement for IMO to tackle such attitudinal barriers in order to realise the coveted outcomes. As such, Table 2, created for the purpose of summarising the results, enhances our understanding of how different organisational approaches engender different employee outcomes. In particular, it serves to illustrate two distinct differences that emerged from the data. 
Table 2 Summary of results

\begin{tabular}{|c|c|c|c|c|c|c|}
\hline \multirow[t]{2}{*}{ Participant } & \multirow{2}{*}{$\begin{array}{l}\text { Brand knowledge } \\
\checkmark=\text { unprompted } \\
X=\text { prompted }\end{array}$} & \multicolumn{3}{|c|}{ Provision of information } & \multirow[t]{2}{*}{ Critical success factors } & \multirow{2}{*}{$\begin{array}{l}\text { Commitment } \\
\checkmark=\text { to the brand } \\
x=\text { to the job }\end{array}$} \\
\hline & & Technical & Customer & $\begin{array}{l}\text { Informal (work } \\
\text { environment) }\end{array}$ & & \\
\hline I & $x$ & $\checkmark$ & $\checkmark$ & $\checkmark$ & $\begin{array}{l}\text { - Team environment } \\
\text { - Shared goals }\end{array}$ & $\checkmark$ \\
\hline 2 & & $\checkmark$ & & $\checkmark$ & $\begin{array}{l}\text { - Lead by example } \\
\text { - Respect }\end{array}$ & $x$ \\
\hline 3 & $\checkmark$ & $\checkmark$ & $\checkmark$ & $\checkmark$ & $\begin{array}{l}\text { - Positive work environment } \\
\text { - Acknowledgement }\end{array}$ & $\checkmark$ \\
\hline 4 & $\checkmark$ & $\checkmark$ & $\checkmark$ & $\checkmark$ & $\begin{array}{l}\text { - Personalised service } \\
\text { - Care factor }\end{array}$ & $\checkmark$ \\
\hline 5 & $x$ & $\checkmark$ & & $\checkmark$ & $\begin{array}{l}\text { - Articulation of a vision } \\
\text { - Positive work environment }\end{array}$ & $x$ \\
\hline 6 & $\checkmark$ & $\checkmark$ & $\checkmark$ & $\checkmark$ & $\begin{array}{l}\text { - Leader } \\
\text { - Positive work environment }\end{array}$ & $\checkmark$ \\
\hline 7 & $\checkmark$ & $\checkmark$ & $\checkmark$ & $\checkmark$ & $\begin{array}{l}\text { - Support } \\
\text { - Positive relationships }\end{array}$ & $\checkmark$ \\
\hline 8 & $\checkmark$ & $\checkmark$ & $\checkmark$ & $\checkmark$ & $\begin{array}{l}\text { - Resources-team and technical } \\
\text { - Synergy with organisational values }\end{array}$ & $\checkmark$ \\
\hline 9 & & $\checkmark$ & & $\checkmark$ & $\begin{array}{l}\text { - Organisational information } \\
\text { - Support }\end{array}$ & $x$ \\
\hline 10 & & $\checkmark$ & & & $\begin{array}{l}\text { - Communication } \\
\text { - Positive work environment }\end{array}$ & \\
\hline
\end{tabular}

The first group consists of respondents $1,3,4,6,7$ and 8 while the second group consists of respondents 2, 5 and 9. At first glance, the commonality that these respective groups share can be classified in accordance with their level of commitment or relationship with their organisation's brand. A closer look will also reveal another distinct difference between the groups, that being their exposure to information that connects them to the brand, namely the customer/market information.

In all three cases where the respondents indicated, directly or indirectly, that they were not exposed to this type of information, they could not articulate what their organisation's brand was or see any real difference from what competitors offered. Furthermore, while the respondents indicated a level of commitment, it was inwardly motivated, engendered through the synergy between their personal values and their chosen profession, completely separate from the organisation. In other words, they were all committed to doing a good job but it was motivated by the ability to develop skills that would open more doors for them professionally, outside of their current organisation.

This amplifies the thinking promoted by Reichheld and Rogers, ${ }^{36}$ who suggest that organisations wanting to inspire employees require the communication of clear goals that are personal and immediate in order for employees to engage. Without answering for the employees 'What's in it for me?' the connection between the brand and the employee is lost. $^{52}$ Sartain and Schumann ${ }^{52}$ (p. 42) believe that employees must understand the purpose of the business 'what difference does the business make to its customers. Why you exist and how your business creates a relationship with its 
customers' in order for them to be able to support the customer strategy and, in turn, feel valued and appreciated. From this perspective, it is suggested here that there is a link between employees being provided with customer/market information and employee perception as to the extent to which the organisation values employee contribution. By providing employees with information that is beyond the 'technical' requirements, employees interpret such action as being indicative of the organisation's respect for employees' impact on organisational outcomes. Consequently, employee effort, or commitment, is commensurate to the perceived 'care factor' of the organisation.

As a result of the linkage between employee commitment and the provision of information employees perceive to be necessary for the successful execution of their job, the findings presented in Table 2 suggest that the adoption of a traditional human resource approach to the development of skills and knowledge that is training, within an organisation is insufficient. Concern for an employee's ability (how the employee is supposed to do their job) to perform is often all that is considered important, or all that the employee 'needs', to do their job effectively. ${ }^{45,51}$ In order to create a synergy or a bond between the employee and the organisation, however, that is considered significant enough for the employee to not only be able to, but more importantly, motivated to deliver the brand promise, a more broader or a richer approach to knowledge creation is required. Such an approach acknowledges an employee's 'need' to go beyond ability, to encapsulate attitude (how the employee feels about what they are doing), as well as awareness (employee comprehension as to what they are supposed to be doing). ${ }^{51}$

According to Thompson, ${ }^{51}$ (p. 15) 'in order to entice people to do anything that needs some form of persuasion, it is necessary to find out what creates or reinforces the "need" for them to want to act in a positive and motivated way'. That is, employees need more information than just technical competency in order to deliver the brand promise, as was evidenced in the findings of this study. Exposure to customer/market information in conjunction with training and exposure to the general work environment enables that depth of brand knowledge necessary to deliver the brand promise. The provision of technical information as facilitated through training is still a significant component for employee success. Alone, however, it does not deliver long-term benefits for the organisation, as employees seek to transport their enhanced functional skills elsewhere. Rather, long-term benefits are bestowed upon an organisation that adopts a broader or a holistic approach to IMO through increased employee commitment and emotional attachment to the brand. Just as the organisation's brand is considered to be shorthand for an emotional connection with customers, the brand internally is considered to possess the same short-hand qualities with employees. ${ }^{52}$ It serves as the basis for motivating employees to want to deliver the brand promise and, in turn, frames how to foster a working environment that retains, as well as attracts, prospective employees. ${ }^{52}$

\section{CONCLUSIONS AND IMPLICATIONS}

As was premised in the literature review, investment in an organisation's human capital is a precursor for subsequent organisational success, especially in such a competitive global market. While conceptually this appears to be a reasonable assumption, the empirical evidence is 
limited to the validation of the link between employee satisfaction and customer loyalty. ${ }^{53}$ In particular, internal brand management has been identified as a means to engender such outcomes (eg organisational success and employee satisfaction) and yet there appears to be limited understanding as to the impact of such efforts from an employee perspective. Without such insight, attainment of a desired level of employee satisfaction could be considered synonymous to 'flying blind'. Furthermore, it becomes increasingly challenging to justify such an internal investment without evidence of the impact such an investment has on the organisation as manifested in employee attitude and behaviour.

The Employee Brand Commitment Pyramid (EBCP), shown in Figure 1, encapsulates the contributions of this study through depicting the building blocks in creating employee commitment to the brand. The foundation of the EBCP represents rudimentary-level information such as technical (or task-associated) information, which, at minimum, needs to be provided to employees in order for them to undertake the tasks associated with their jobs. Employees having access to adequate and appropriate technical information is likely to result in employees having commitment to their respective jobs but, at this point, nothing further. Employees who are then provided with appropriate brand-related information, however, move to the top of the pyramid as they develop a strong commitment to the brand.The degree to which employees are supported by the organisation in their progression to the top of the pyramid may well dictate the organisation's ongoing success and sustainability of a strong brand.

It is evident from the results of this study that employee access to brandrelated information, in addition to the more traditional forms of internally generated organisational information, resulted in a strong allegiance to the organisation. As such, the findings of this study indicate that there is a tangible benefit, that is, employee brand commitment that accrues to an organisation that effectively adopts an internal brand management philosophy. Just as customers having knowledge of the brand is considered to be the driving force of organisational benefits, as manifested in brand equity, ${ }^{54}$ employees having knowledge of the brand is also to considered to be significant in deriving significant benefits for the organisation.

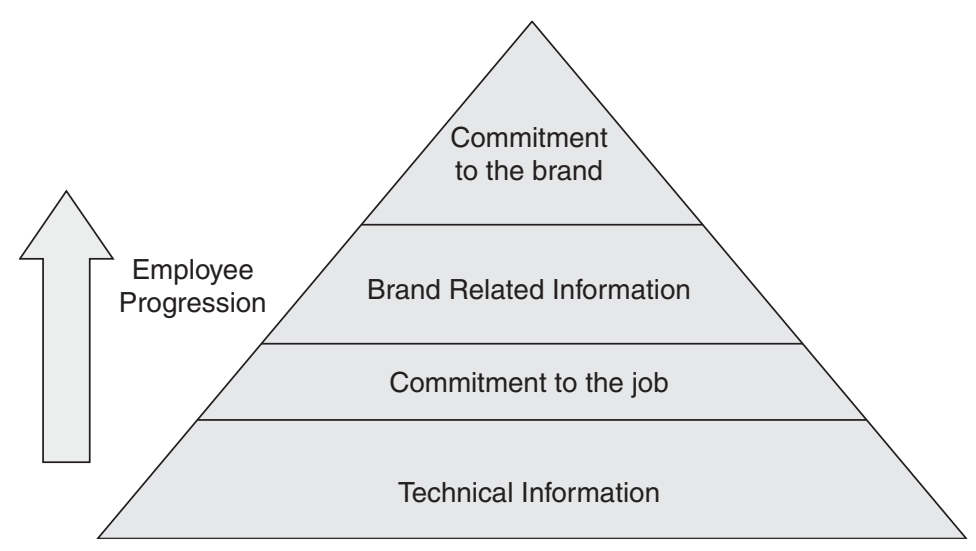

Figure I Employee brand commitment pyramid (EBCP) 


\section{References}

(1) Henkoff, R. (1994) 'Service is everybody's business', Fortune, Vol. 129, No. 13, p. 48-54.

(2) Vargo, S. L. and Lusch, R. F. (2004) 'Evolving to a new dominant logic for marketing', Journal of Marketing, Vol. 68, No. 1, pp. 1-17.

(3) Pappu, R., Quester, P. G. and Cooksey, R. W. (2005) 'Consumer-based brand equity: Improving the measurement-empirical evidence', The Journal of Product and Brand Management, Vol. 14, No. 2/3, pp. 143-154.

(4) Lings, I. N. (2004) 'Internal market orientation: Construct and consequences', Journal of Business Research, Vol. 57, No. 4, pp. 405-413.

(5) Burmann, C. and Zeplin, S. (2005) 'Building brand commitment: A behavioural approach to internal brand management', Journal of Brand Management, Vol. 12, No. 4, pp. 279-300.

(6) Devlin, J. F. and Azhar, S. (2004) 'Life would be a lot easier if we were a Kit Kat: Practitioners' views on the challenges of branding financial services successfully', Journal of Brand Management, Vol. 12, No. 1, pp. 12-30.

(7) de Chernatony, L. and Dall'Olmo Riley, F. (1998) 'Modeling components of the brand', European Journal of Marketing, Vol. 32, No. 11/12, pp. 1074-1090.

(8) Wernerfelt, B. (1984) 'A resource-based view of the firm', Strategic Management Journal, Vol. 5, pp. 171-180.

(9) Martin-de-Castro, G., Navas-Lopez, J. E., LopezSaez, P. and Alama-Salazar, E. (2006) 'Organizational capital as competitive advantage of the firm', Journal of Intellectual Capital, Vol. 7, No. 3, pp. 324-337.

(10) Dierickx, I. and Cool, K. (1989) 'Asset stock accumulation and sustainability of competitive advantage', Management Science, Vol. 35, pp. 1504-1513.

(11) Grant, R. M. (1996) 'Prospering in dynamicallycompetitive environments: Organizational capability as knowledge integration', Organization Science, Vol. 7, No. 7, pp. 375-388.

(12) Leonard-Barton, D. (1992) 'Core capabilities and core rigidities: A paradox in managing new product development', Strategic Management Journal, Vol. 13, pp. 111-125.

(13) Nonaka, I. (1991) 'The knowledge-creating company', Harvard Business Review, Vol. 69, pp. 96-104.

(14) Prahalad, C. and Hamel, G. (1990) 'The core competence of the corporation', Harvard Business Review, Vol. 90, pp. 79-91.

(15) Constantin, J. A. and Lusch, R. F. (1994) 'Understanding Resource Management', The Planning Forum, Oxford, OH.

(16) Pfeffer, J. (1995) 'People, capability and competitive success', Management Development Review, Vol. 8, No. 5, pp. 6-11.
(17) Edvinsson, L. (1978) 'The new business focus', The Services Industries Journal, Vol. 7, No. 2, pp. 195-206.

(18) Pfeffer, J. and Veiga, J. (1999) 'Putting people first for organisational success', The Academy of Management Executive, Vol. 13, No. 2, pp. 37-48.

(19) O'Reilly III, C. and Pfeffer, J. (2000) 'Unlocking the hidden value in organizations', Employment Relations Today, Vol. 27, No. 2, pp. 63-80.

(20) Ramlall, S. (2004) 'A review of employee motivation theories and their implications for employee retention within organizations', The Journal of American Academy of Business, Vol. 5, No. $1 / 2$, pp. 52-63.

(21) Keller, K. L. (1998) 'Strategic Brand Management', Prentice-Hall, Upper Saddle River, NJ.

(22) Berry, L. L. (2000) 'Cultivating service brand equity', Academy of Marketing Science. Journal, Vol. 28, No. 1, pp. 128-137.

(23) Jacobs, R. (2003) 'Turn employees into brand ambassadors', ABA Bank Marketing, Vol. 35, No. 3, pp. 22-26.

(24) Ind, N. (2003) 'Inside out: How employees build value', Journal of Brand Management, Vol. 10, No. 6, p. 393.

(25) Aurand, T. W., Gorchels, L. and Bishop, T. R. (2005) 'Human resource management's role in internal branding: An opportunity for crossfunctional brand message synergy', The Journal of Product and Brand Management, Vol. 14, No. 2/3, pp. 163-169.

(26) Miles, S. J. and Mangold, G. (2004) 'A conceptualization of the employee branding process', Journal of Relationship Marketing, Vol. 3, No. 2/3, p. 65.

(27) Webster, C. (1992) 'What kind of marketing culture exists in your service firm? An audit', Journal of Services Marketing, Vol. 6, No. 2, p. 54.

(28) Berry, L. L., Zeithaml, V. and Parasuraman, A. (1990) 'Five imperatives for improving service quality', Sloan Management Review, Vol. 31, No. 4, p. 29.

(29) Kunda, S. C. and Vora, J. A. (2004) 'Creating a talented workforce for delivering service quality', Human Resource Planning, Vol. 27, No. 2, p. 40.

(30) Cannon, D. F. (2002) 'Expanding paradigms in providing internal service', Managing Service Quality, Vol. 12, No. 2, p. 87.

(31) Tosti, D. T. and Stotz, R. D. (2001) 'Brand: Building your brand from the inside out', Marketing Management, Vol. 10, No. 2, pp. 28-33.

(32) Gronroos, C. (1990) 'Relationship approach to marketing in service contexts: The marketing and organizational behavior interface', Journal of Business Research, Vol. 20, No. 1, pp. 3-11.

(33) Narver, J. C. and Slater, F. (1990) 'The effect of market orientation on business profitability', Journal of Marketing, Vol. 54, No. 4, pp. 16-35. 
(34) Kohli, A. and Jaworski, B. J. (1990) 'Market orientation: The construct, research propositions, and managerial implications', Journal of Marketing, Vol. 54, No. 2, pp. 1-18.

(35) Kohli, A. and Jaworski, B. J. (1993) 'Market orientation: Antecedents and consequences', Journal of Marketing, Vol. 57, No. 3, pp. 53-70.

(36) Reichheld, F. and Rogers, P. (2005) 'Motivating through metrics', Harvard Business Review, Vol. 83, No. 9, pp. 20 and 24.

(37) Herzberg, F. (2003) 'One more time: How do you motivate employees', Harvard Business Review, Vol. 81, No. 1, pp. 86-96.

(38) Haley, E. (1996) 'Exploring the construct of organization as source: Consumer's understanding of organizational sponsorship of advocacy advertising., Journal of Advertising, Vol. 25, No. 2, pp. 19-29.

(39) Hastings, K. and Perry, C. (2000) 'Do services exporters build relationships? Some qualitative perspectives', Qualitative Market Research: An International Journal, Vol. 3, No. 4, pp. 207-214.

(40) Masberg, B. A. and Silverman, L. H. (1996) 'Visitor experiences at heritage sites: A phenomenological approach', Journal of Travel Research, Vol. 34, No. 4, pp. 20-28.

(41) Marshall, C. and Rossman, G. B. (1999) 'Designing Qualitative Research', 3rd edn, Sage Publications, California.

(42) de Chernatony, L. and Dall'Olmo Riley, F. (1997) 'The chasm between managers' and consumers' views of brands: The experts' perspectives', Journal of Strategic Marketing, Vol. 5, pp. 89-104.

(43) Asif, S. and Sargeant, A. (2000) 'Modelling internal communication in the financial services sector', European Journal of Marketing, Vol. 34, No. 3/4, pp. 299-318.

(44) Grace, D. and O'Cass, A. (2002) 'Brand associations: Looking through the eye of the beholder', Qualitative Market Research: An International Journal, Vol. 5, No. 2, pp. 96-111.
(45) Thomson, K. and Whitwell, K. (1993) 'Managing Your Internal Customers', Pitman Publishing, London, UK.

(46) Aselage, J. and Robert, E. (2003) 'Perceived organizational support and psychological contracts: A theoretical integration', Journal of Organizational Behavior, Vol. 24, pp. 491-509.

(47) Keller, S. B. (2002) 'Internal relationship marketing: A key to enhanced supply chain relationships', International Journal of Physical Distribution \& Logistics Management, Vol. 32, No. 8, pp. 649-668.

(48) Ballantyne, D. (2000) 'Internal relationship marketing: A strategy for knowledge renewal', The International Journal of Bank Marketing, Vol. 18, No. 6, p. 274.

(49) Morgan, R. M. and Hunt, S. D. (1994) 'The commitment-trust theory of relationship marketing', Journal of Marketing, Vol. 58, No. 3, p. 20.

(50) Castro, C. B., Armario, E. M. and Elena Sanchez del Rio, M. (2005) 'Consequences of market orientation for customers and employees', European Journal of Marketing, Vol. 39, No. 5/6, pp. 646-675.

(51) Thomson, K. (1990) 'The Employee Revolution-Corporate Internal Marketing', Pitman Publishing, London, UK.

(52) Sartain, L. and Schumann, M. (2006) 'Brand from the Inside: Eight Essentials to Emotionally Connect Your Employees to Your Business', John Wiley \& Sons, San Francisco, CA.

(53) Lovemann, G. W. (1998) 'Employee satisfaction, customer loyalty and financial performance-An empirical examination of the service profit chain in retail banking', Journal of Service Research, Vol. 1, No. 1, pp. 18-31.

(54) Keller, K. L. (1993) 'Conceptualizing, measuring and managing customer based brand equity', Journal of Marketing, Vol. 57, No. 1, pp. 1-22. 